Fecha de recepción: mayo 2020 Fecha de aceptación: junio 2020 Versión final: julio 2020

\section{Abstracciones filosóficas acerca del ethos del Diseño}

Luz del Carmen Vilchis ${ }^{(*)}$

\begin{abstract}
Resumen: Ethos es el principio que debiera estimular a todo diseñador, es una suerte de lar interior en el cual se desarrolla la conciencia propia y el mundo donde es y existe. En el ethos el diseñador se conoce y reconoce a sí mismo, en él reside su discernimiento y cobra sentido el cúmulo de relaciones en las que se expresa a sí mismo, él alienta la conducta que le da existencia y unifica su capacidad para construir el lugar donde encuentra seguridad y resguardo su bien vivir y el de los otros. Una existencia privada de ser y vida convierte al ethos en pathos que pierde al diseñador en la nada. Nunca antes los recursos tecnológicos habían permitido la construcción de un sistema tan completo y eficaz de dominio para diseñar mediante la explotación del propio ímpetu, que en más de un sentido es reflejo de esa realidad que pesa sobre las masas atomizadas y entristecidas, aisladas en sus mundos propios que se reconocen como fugas de un contexto en el que no pueden vivir, el que ha dejado de ser un hogar. Por lo anterior las relaciones epistemológicas del Diseño se abaten en un proceso de ideologización absoluta, eliminando la controversia teórica y dando paso al dominio mono-cultural que destruye pensamiento y saber mediante la reducción de la capacidad crítica y la conciencia ética que produce al diseñador infralógico e infraético, protagonista de la quiebra de los valores de la postmodernidad que termina por negar el concepto y el mundo donde el diseñador es y actúa. Parecen olvidadas las concepciones del diseño y los diseñadores como efecto de los más altos desarrollos de la cultura y la civilización que Tomás Maldonado, refiriendo a la dialéctica, enunció como las más fecundas trayectorias de la exploración científica acerca de las objetividades y subjetividades de la praxis humana. Este artículo postulará un nuevo principio para ethos y diseño.
\end{abstract}

Palabras clave: ética - diseño - abstracción - reflexión - praxis

[Resúmenes en inglés y portugués en las páginas 116-117]

(*) Catedrática de la Facultad de Artes y Diseño-UNAM desde 1979. Pertenece al Sistema Nacional de Investigadores (CONACYT) Nivel II. Licenciada en Diseño Gráfico, Filosofía y Psicología; Maestra en Comunicación, Diseño Gráfico y Neuropsicología; Doctora en Bellas Artes por la Universidad Politécnica de Valencia; Filosofía en la UNAM, Docencia en Artes y Diseño en la UNAM y Honoris Causa en Filosofía Educativa por el Consejo Iberoamericano de Uruguay. Autora de 44 libros originales, 40 capítulos y 147 artículos internacionales y manuales especializados. Directora de 275 tesis de licenciatura, maestría y doctorado, ha dictado 93 cursos y 210 conferencias internacionales en 42 países. Reconocida con premios internacionales por su labor académica y de investigación. linusviel@gmail.com 
Tú no puedes comprar al viento

Tú no puedes comprar al sol

Tú no puedes comprar la lluvia

Tú no puedes comprar el calor

Tú no puedes comprar las nubes

Tú no puedes comprar los colores

Tú no puedes comprar mi alegría

Tú no puedes comprar mis dolores

(Calle 13, Latinoamérica)

\section{Preámbulo sobre el ethos}

Ethos es origen y principio en la vida de todo ser humano y se traduce en el principio rector de la conducta individual y social, es el fundamento de los valores que se traducen en el desempeño cotidiano des ser en sí y el ser en sociedad; este umbral incentiva tanto al diseñador como a su consciencia y por ende al entorno donde es y donde existe. En el ethos el diseñador se conoce y reconoce a sí mismo, en él reside su discernimiento y cobra sentido el cúmulo de vínculos con los que se proyecta expresando su sí mismo; bajo estos términos la conducta integra el existir a la capacidad de integrar el propio buen vivir con la otredad, entendiendo esto último como la posibilidad de ejercer la crítica. (Gudynas, 1999: 9) En el ethos se encuentran en fusión permanente el pasado, el ahora y las prospectivas con las que un diseñador de inventa y reinventa respecto a los diversos contextos con los que debe interactuar, es pensamiento teórico y valorativo ligado indisolublemente en la trama que cada individuo teje con su vida.

El ethos es intelección del bien humano aunado al espíritu que configura los valores del uno y de los otros; sugiere siempre un orden de pensamientos y acciones sentando los valores y principios bajo los que la individualidad se abre para materializar los fines del diseño. Con base en lo anterior es que surgen para el diseñador derechos y obligaciones para sí y para los otros; es posible afirmar que la cotidianeidad constituye la cultura axiológica.

En cualquier caso, el punto de vista de la teoría axiológica (la que se propone acentuar la importancia de los «valores» en el análisis de lo social) va a exigir en paralelo una tendencia hacia la mejor integración y síntesis posibles de las teorías, puntos de vista, perspectivas, métodos y técnicas que se consideren más adecuadas en cada momento y contingencia. (Parra, 2004, p. 33)

El ethos subyace en toda manifestación del yo del diseñador, sustenta su identidad, pensar y actuar encuentran en él, se trata de esa rezón interna que se reconoce en palabras, grafías y señales, en denotaciones y connotaciones. Es la consciencia que marca lo similar y lo distinto y deviene en normas individuales y colectivas, en estilos expresivos y escuelas de pensamiento acerca del diseño y el diseñar. Este ser conlleva los criterios acerca de bien y 
mal, de correcto e incorrecto, de viable e inviable teñidos por coyunturas históricas sin que la pluralidad o indeterminación modifiquen la esencia absoluta y objetiva de su condición normativa. El ethos se ve afectado cuando la atonía o laxitud conduce a la enajenación cuya dejadez sólo evoca los perfiles sofistas.

En el sentido más fuerte y amplio no hay diseño sin ethos; diseñar supone delimitaciones éticas que inclinan la balanza de la praxis hacia las condiciones de verdad del hacer, el crear y el comunicar en su más profunda percepción. ¿Qué diseñar? Esta pregunta entraña una actitud ética en razón de los fines que el diseñador se propone e implica decisiones acerca de lo que se quiere saber del mundo donde se actúa y se construye un territorio compartido. El ethos no es otra cosa que la certeza del diseñador, por la cual éste da cuenta de su estar y hacer en el mundo, de ahí que las dificultades éticas en el Diseño sean, en su fundamento, crisis de logos -razón y la palabra- y praxis -acción- que en la actualidad y como efecto de las presiones que ejerce la globalización se encuentre, como disciplina a la deriva entre la pragmática reduccionista y la institucionalidad comercializada. Este fenómeno se encuentra apoyado permanentemente por los medios de comunicación que propician la cosificación del sujeto y las imposiciones del mercado.

Todo trance o barrera del diseño es un asunto ético, implica el destierro de la razón del mundo de lo diseñado, abarca desde las organizaciones que verifican los valores del diseño hasta la consciencia personal... significa la pérdida del mundo común compartido donde el diseñador se concibe a sí mismo, la desintegración y el retraimiento que lo ahogan en la vaciedad, en la enajenación del yo. Rescatar el espíritu y el ethos del diseño obliga a restaurar elementos que conciban a la disciplina, dese una óptica holística en la que todos los planos de la razón y las múltiples interacciones no se pierdan para concluir siempre en el todo.

El punto de encuentro primordial para el diseñador es el reconocimiento de las necesidades y su consiguiente relación estructural ara constituirlas en problemática, todo ello desde una universalidad ineludible. La ética en desde este origen proyectual tiene como denominadores comunes la responsabilidad social y el trabajo en pro del buen vivir. Aquí el diseñador ha de mantener al margen al yo y dar paso a la otredad, los momentos del yo están moderados por el bien común. El resultado, lo diseñado, inevitablemente tendrá la huella del diseñador, no obstante, se orientará por los fines que le son propios. Es la visión de la alteridad

La ética del Diseño de uno de los fundamentos del bien vivir, es resultado del hacer del "yo" en este mundo en relación con los otros "yos", en comunidad trascendente de hacer obra común que une e identifica, proporciona identidad y pertenencia en el ser reconociendo a cada yo en su relación con la universalidad. Implica desde el saber y valorar que guían hacia fines propios, hasta la comunidad de ser y hacer que constituye el entorno del diseñador, tan amplio trascendente y pleno como lo concibe en sus fines axiológicos.

El otro u otro constitutivo (también conocido como alteridad), constituyen un concepto clave de la Filosofía continental. Es una idea opuesta a la identidad y se refiere, o se intenta referir, a aquello que es "otro" frente a la idea de ser considerado algo. El otro, considerado siempre como algo diferente, alude a otro individuo más que a uno mismo y normalmente se escribe en mayúscu- 
las. La noción de "otredad" forma también parte integral de la comprensión de una persona, ya que es el individuo mismo el que asume un rol en relación con "otros" como parte de un proceso de reacción [...] (Fandiño, 2014, p. 50)

La ética proporciona al Diseño criterios precisos y particulares desde conceptos universales, enlazados por reglas de concomitancia que establecen una escala disciplinaria de valores. El sentido de lo diseñado depende del ejercicio del albedrío creador, es una capacidad a la que no se renuncia y por ende supone toda la responsabilidad sobre su contenido. La trascendencia del Diseño es una consecuencia a la que se apuesta desde el proceso proyectual el cual, si no trabaja los trasfondos conceptuales, se vuelve prisionero de la inmanencia del instante en que se agota todo "aquí y ahora..."

Privado de la libertad de involucrarse con el entorno en su totalidad, todo diseño es en y para la nada, fuera del mundo, donde el diseñador se debate en entredichos porque existe extraviado de sí, sin ser, en su ensimismamiento y su soledad, por haber perdido con el mundo de la vida y el ser su identidad, por no saberse a sí mismo como verdad para la vida y no encontrar por la incomunicación de su existencia el tú o el otro, ontológica y axiológicamente necesario. La existencia privada de ser y vida convierte al ethos en pathos que pierde al diseñador en la nada.

\section{La pertenencia y sus contextos conceptuales}

Desde los griegos hasta las teorías contemporáneas de las necesidades, se acepta que los individuos requieren reconocerse, primero a sí mismos, en una aceptación tácita de sus cualidades y aptitudes, de sus limitaciones e inconvenientes. Después, está la exigencia ética de la otredad, es decir, la identificación con los seres humanos que nos rodean, es la adquisición de certeza acerca de la pertenencia a un espacio y un tiempo, a diversos grupos que definen y acotan socialmente.

La identidad es el conjunto acoplado de características de un individuo o grupo que se constituyen como un sistema simbólico y de valores, ético, con base en el cual se encaran situaciones cotidianas. Es un tamiz que sustenta su análisis y comprensión. Es el digesto que cada persona lleva a cabo de los indicios de proceder, comunicados por diversas vías sociales. Cada quien asimila estos principios conforme a su experiencia y su conciencia individual. (Balzat, 2002)

El concepto de identidad transita entre tres vertientes que lo manejan de acuerdo a una serie de conveniencias. Se encuentra la idea tradicional, surgida de la filosofía, la antropología y en general de las humanidades, según la cual, la identidad forma parte esencial de la vida de los pueblos que, sin ella, no encuentran su lugar y la certeza de su ser y existir. Frente a un concepto fuerte se ubican tanto el modernismo como el posmodernismo, ambos han desarrollado teorías que consideran a la identidad un estigma, una noción desgastada. El modernismo, a pesar de ello, reconoce que existe la identidad aunque denomina a los individuos quienes la ostentan de manera legítima como "marginales" (Goffman, 2012: 
139), término despectivo que señala los códigos de conducta como estandarizaciones desde las cuales los individuos son entes manipulables.

El posmodernismo en definitiva anula toda posibilidad de filiación social, ya que, aseguran teóricos como Lipovetsky (2014), Bauman (2011) y Hall (1992), el actual ritmo de la civilización, fluido y vacío, además de transformarla en un elemento acuoso que no se puede detener, ha generado sujetos en constante cambio. Los seres humanos, desde esta visión, no tienen una identidad estable, esta se encuentra en constante devenir, (Hall, 1992) dependiente de los sistemas culturales y por ende, no hay forma de definir sus modos. Bauman (2011, p. 41) afirma que pensamos en la identidad "cuando no estamos seguros del lugar al que pertenecemos", es decir, cuando estamos inseguros acerca de nuestra ubicación en le diversidad de formas de comportarse y con ello lograr que quienes nos rodean lo conozcan y acepten como asertivo y apropiado, todo ello con objeto de que los involucrados tengan la certeza de cómo interactuar. Identidad es le denominación otorgada a los intentos de salir de la incertidumbre.

En definitiva este momento se explica con uno de los grandes fundamentos tanto del neoliberalismo, como de la globalización. Si no tenemos identidad, luego entonces deambulamos en el mundo y estamos a merced de sus determinaciones dictadas por las grandes economías. Decretar que no existe la identidad significa rebasar al colonialismo y el imperialismo que buscaban el territorio y el capital para abrir las puertas al mundo globalizado, ese de la mono-cultura en el que hay que seguir los dictados de las cúpulas de poder.

En esta disertación, se toma como sustento el concepto recio y determinante de la teoría tradicional, aquél en el que, según Giddens (1990, p.37-38) los grupos humanos se constituyen en sociedades identificadas por el origen y el pasado en común, por valores, usos y tradiciones que prolongan las costumbres y las lecciones aprendidas generación tras generación. La idea que se retoma, rebasa el instante nihilista, regresando a la fusión de pasado, presente y futuro como la alternativa de los pueblos de dar forma a sus vidas con prácticas sociales que los hacen únicos e irrepetibles.

\section{Reflexiones sobre el pathos instrumental y la tecnología}

Cuando el diseñador lleva a cabo esfuerzos de adaptación a las nuevas tecnologías para satisfacer la emergencia del ser contemporáneo, acude a la razón instrumental, privilegiando la importancia y trascendencia de la acción por encima incluso de la conceptuación y de la identidad propia y de la disciplina. Es así que lo diseñadores, al igual que los profesionales de otras disciplinas, empieza a considerar ideas, objetos y todo tipo de elemento como medios para alcanzar dichos fines, ello explica que en la actualidad a todo se le denomine "herramienta" como una de las tantas contribuciones de la globalifilia.

Esta época se puede describir como un parteaguas para el diseño ya que los recursos tecnológicos han posibilitado la construcción de un mecanismo eficiente para diseñar mediante la explotación de la intuición y el ímpetu, el accidente virulento que refleja en diversos aspectos la violencia y la cruda realidad triste y atomizada que encaran las re- 
cientes generaciones. Los diseñadores, más que nunca, se apartan en mundos personales, solitudes que a veces se explican como evasiones o filtraciones de ese exterior en el que no pueden vivir o trabajar como esperaban ya que no lo identifican como su morada. La enajenación del Diseño empieza en el no saber, en la imposibilidad de conocer que se da hoy, paradójicamente, por el exceso de información que impide el conocimiento y la determinación de criterios de verdad, ahogada en el caos del mundo.

Lo que Fromm considera punto central del carácter social del hombre en el capitalismo contemporáneo es la enajenación. Esta visión es deudora de Marx, el cual toma la idea de Hegel y la traslada de un plano espiritual y abstracto a la realidad económica, según la cual 'es necesario liberar al hombre de la esclavitud originada por el trabajo que no le pertenece (el "plus" del trabajo) y alcanzar así una libertad en sentido positivo' [...] Fromm afirma que el concepto de la enajenación toca el nivel más profundo de la personalidad y, además, resulta el más apropiado si consideramos primordial conocer la interacción entre la estructura socioeconómica y la estructura del carácter del individuo medio. (Fernández, 2009, p. 64)

El caos informativo destierra al diseñador del ser y de sí mismo, cosificándolo, haciéndole padecer la brevedad y el apuro del existir y el tener, que se transforman en una cascada encadenada -con todas las acepciones del término- de experiencias no vicariales y en un inventario sumamente pobre en fondo de marcas y palabras. Es el diseño construido a la medida de promotores, patrocinadores y publicistas, tejedores de pasiones que apresan la conciencia con los recursos de la razón instrumental, objetivada como técnica de dominación hecha palabra e imagen, vacías ambas, que convierten a lo diseñado en obra del narcisismo con la consecuente pérdida de identidad.

El caos del diseño vacío y sin sentido lleva a la concurrencia de dos fenómenos: por un lado la condición que anula las diferencias entre sujeto y objeto, por otro el destierro de la razón sumada a la carencia de ser y pensar. Lo anterior pierde al diseñador en un mundo donde se iguala verdad y mentira, libertad y enajenación, virtud y vicio, valor e interés por el proceso, según Toynbee "de barbarización electrónica de las costumbres" (1974) donde el ethos queda sin condición de posibilidad al grado de advenirse impronunciable. El lenguaje visual, convertido en "exiliado" sea como lo entiende Maquiavelo en calidad de ocultación (2010) o como lo afirma Wittgenstein un disfraz del pensamiento en forma tal "que de la forma externa del ropaje no puede deducirse la forma del pensamiento" (1989, p. 4.002) El pensamiento instrumental convierte al diseñador en un incauto operador de subterfugios tecnológicos, práctica en la que se disgregan las precisiones éticas y su trascendencia presentando una situación causa-efecto en la que conducta como pauta se transforma en comportamiento como hábito, los hechos son los que interesan, la actuación por encima de toda razón, la forma sobre el fondo o sin él. Este realismo ingenuo es la mejor evidencia de la carencia de valores éticos o, como lo enuncian los filósofos, la orilla del nihilismo axiológico. Si bien es cierto que toda concepción ética ha de ser valorada desde categorías y conceptos objetivos y racionales, el empirismo materialista que dirige todo hacia los trazos proyec- 
tuales y sus resultados, ha engendrado nichos de subjetividad en los que todo fundamento se reduce a la utilidad de lo diseñado adoleciendo de ideas, supuestos, proposiciones y conclusiones soportados por la teoría. Lo anterior se explica desde el término el neologismo adiáfora postulado por Zygmunt Bauman (2015) aludiendo a la concurrencia de "situar ciertos actos o categorías de los seres humanos fuera del universo de evaluaciones y obligaciones morales..." lo cual tiene como consecuencia la "ceguera moral."

Estos fenómenos se entienden al estudiar los términos del funcionalismo y sus afanes por enajenar al individuo en beneficio de la potestad sociopolítica, económica y sobre todo mercadotécnica. La visualidad ha apartado de sí numerosos principios éticos para responder a las exigencias del mercado: regulaciones, instancias de decisión, legitimación de concepciones ajenas al desarrollo natural de los individuos, etc. Las poderosas trasnacionales sancionan o aprueban requisitos que sirven para legitimar sus "códigos deontológicos" que en mucho trastocan los códigos naturales y las legislaciones marginando así al ethos.

Los vínculos epistemológicos del diseño sustentados bajo términos impuestos y lejanos de las normas que emanan de la separación conceptual entre verdad y falsedad, se desbaratan en una secuencia de derrotas por las que se adoptan idearios carentes de bases teóricas. La monocultura destruye pensamiento y saber y abre el paso al diseñador infralógico $e$ infraético, protagonista de la quiebra de los valores de la postmodernidad que termina por negar el concepto y el mundo donde el diseñador es y actúa. Así empiezan consignas como: internacionalízate, la verdad es tecnología y el mundo es un negocio..., ellas reducen la idoneidad de la crítica y la consciencia ética que provoca.

\section{Los estereotipos sociales y la ruptura de la identidad}

Coincidiendo con las ideas expresadas por los teóricos posmodernos, en la actualidad se ejerce un poder no visible para propiciar la identificación de la gente con el consumo, aplicando una serie de estrategias ocultas en la propaganda publicitaria para persuadirla de adquirir productos a través de los cuales "aparentemente" se apropiarán de una identidad fingida, de un estatus social que les permita introducirse en un determinado nivel de vida. La apertura de las formas ocultas de la propaganda, se basa en un trabajo pionero de Vance Packard (2007) quien investigó los métodos psicológicos para aprovechar nuestros deseos inconscientes con objeto de que la gente se convenciera de aquello que le ofrecen las marcas y los productos. Se postula la tesis de que la motivación inconsciente a través de la comunicación visual es una de las estrategias que se utilizan en la actualidad para crear estereotipos y falsas identidades utilizando técnicas y estrategias que emergen de los estudios de mercado.

Se considera que la acción mimética, propia de la condición humana, conduce a la encarnación de una serie de características que pertenecen a ámbitos diversos, y que permiten reafirmar las diferencias que uno establece respecto a los otros. "La identidad se afirma en la diferencia y el sujeto busca hacer evidente esta presencia que le permite, sin afirmar la exactitud, sí consolidar las afinidades y semejanzas que coinciden con otros." (Heidegger, 
1990: 89) La función más importante de la identidad social es la conformación de paradigmas culturales que sirven de modelo significativo para las comunidades.

A través de los orígenes, la comprensión del pasado, las asociaciones sociales y los hechos trascendentes para los pueblos, el hombre capta los vínculos entre temporalidad, nacimiento, muerte, sexualidad, fertilidad y así sucesivamente para fusionar el contexto intergrupal con la atracción hacia unidades sociales de las cuales se forma parte, propiciando la interdependencia de creencias y la personalización. Las imágenes participan de manera decidida en el proceso de formación de la identidad de los grupos, explicitando los valores en que se reconocen, se consolidan y difunden. Establecen nuestra relación psicológica con el mundo visual para reconocerlo y recordarlo generando funciones simbólicas y representativas, y proyectarlo en esquemas perceptuales que posibiliten dar estructura a la realidad, imaginarla o confrontarla con los datos precedentemente encontrados. (Van Knippenberg, 1999)

Los estereotipos son parte importante del fenómeno de identidad a través de la imagen, al tratar de ser un compendio de características sustanciales presentes en la memoria individual y colectiva del entorno social, es la continuidad psicológica lo que garantiza la identidad personal. A nivel colectivo nuestra identidad social está configurada igualmente por un patrón con recuerdos del pasado. (Azuela, 2005) En la construcción de los procesos de identidad social se recurre a la memoria de referentes como costumbres, actividades, objetos, personas, ideas, para transformarlos en estereotipos; es la persistencia de especificas cargas culturales, que indican "lo que se es, o debe ser, y al tiempo lo que no se es, o no se debe ser", identidades que se validan, adoptan y reproducen. No obstante, pesan también los modelos impuestos por los dominios político, económico y cultural, con sus connotaciones ideológicas que en el trasfondo conciben prototipos universales que tienden a la americanización, como afirma Gilberto Giménez (1995).

El nicho más importante de este juego de poder y sometimiento de las consciencias es la publicidad y su necesario efecto, el consumo. La publicidad vende, antes que los productos, expectativas con base en las más ambiciosas técnicas persuasivas que van desde el slogan hasta el anuncio subliminal. El sondeo y la manipulación de los consumidores se lleva a cabo desde hallazgos de los psicólogos motivacionales y algunas técnicas psicoanalíticas de masas que suman cada vez más elementos explicativos de por qué la gente actúa como lo hace. Así se despliegan estrategias publicitarias de identidad que prometen estatus, belleza, poder, atracción sexual, etc., promoviendo modelos sustentados en tests proyectivos y estudios estadísticos que han subdividido a la población en estratos, asignando a cada uno de ellos condiciones específicas de identidad reflejadas en los anuncios y toda la secuencia de inmersión publicitaria: "Soy totalmente Palacio" es un lema de identidad social cuya fuerza se reconoce en nuestra sociedad, así podemos reconocer desde el nivel social más alto "Hazlo (just do it)", hasta la manipulación de los jóvenes con "Pokémon GO hace posible lo imposible" que ha dirigido las miradas y acciones de millones de niños $\mathrm{y}$ adolescentes en el mundo.

Una parte importante de la ciencia del comportamiento se ha consolidado en una coyuntura social muy importante, porque lejos de esfumarse, y a pesar de que se presenta en forma de "moda" o "tendencia", se fortalece. La publicidad, con sus técnicas de persua- 
sión y la definición de patrones identitarios, satisface necesidades económicas, políticas y socioculturales surgidas a partir de la emergencia de los modelos neo-liberales. Lo que moldea la publicidad no son las directrices de los compradores, se trata de la consciencia de individuos con pensamientos más profundos y expectativas que no tienen que ver con la colocación de productos. El planteamiento de las formas comerciales y el asalto que han ejercido sobre las formas del diseño se ha extendido a otras esferas que es necesario enfrentar desde las derivaciones éticas de su empleo.

La crisis profunda que padecen las relaciones entre la ética y el diseño empieza en el lenguaje artificialmente reducido a su carácter operativo, subordinado al consumismo inherente que incorpora la pérdida de responsabilidad basada en la computarización que también le ha despersonalizado. Los programas de las computadoras puestos en práctica por los diseñadores por su supuesto carácter estrictamente técnico o neutro, en pro de los beneficios espaciales y temporales, despersonaliza el ejercicio humanista, eliminando la responsabilidad ética que se diluye en carencia o excedente de sentido, visiones equivocistas o univocistas que diluyen el justo medio en el eficientismo que actualmente busca instrumentar en la enseñanza del diseño la habilidad de programar invalidando los paradigmas universales del diseño y su campo semántico sustantivo. Así, los afanes se centran en la eficacia funcional y sus impedimentos, identificados con figuras de simulación-como las distinciones de autoría o los genios de pasarela-, argumentados con base en el valor operativo, así surge una pregunta que no se responde en este texto... el diseñador es ¿responsable de qué y ante quién?

La llamada realidad virtual, que ha materializado la utopía de la acción a distancia o el control en soledad, evita toda conciencia personal de responsabilidad al quedar atrapada en la pantalla y hundir al diseñador en la paradoja profunda de la hipermodernidad, interpretada hermenéuticamente: la razón instrumental desemboca en el más agudo absurdo de misantropía y solipsismo, donde el diseñador termina por relacionarse exclusivamente consigo mismo en el mundo virtual y distante, convertido en el centro de su soledad, aislada y hacia adentro, porque ha devenido un extraño en el mundo donde no encuentra lugar y ha dejado de estar. El impulso nihilista o existencial lleva al diseñador a buscar el sentido de su profesión en quimeras, especie de fugas metafísicas por las que se adormece en el no ser de la imagen.

La neo-tecnología electrónica ha dado un nuevo significado ético a las ideas de compañía y responsabilidad en las relaciones virtuales donde el quién, destinatario, y el qué de la relación se desvanecen y con ellos los valores que les rigen. La electrónica ha generado una forma de relación para todo, en particular para el diseño: interactividad virtual, en la que, en verdad, falta la praxis y su carencia o apraxia convierte la relación intersubjetiva, en un nexo desmaterializado donde la mediación aleja en lugar de acercar, conforme a una manera de proceder alógico (carece de lógica) que no puede ser desligado de sus condiciones contextuales, ni soslayar que genera el mundo anético de un ser infraético e infralógico base del poder económico que avasalla la estructura de esta disciplina en el mundo contemporáneo donde la pérdida del sentido de realidad trae por consecuencia la pérdida de identidad, que en este caso apunta al quehacer tanto como a los profesionales. 
Un hombre sin libertad -sin su posibilidad-es un ser infra-ético privado de la responsabilidad de su conducta, de dar cuenta de ella y remitirla a la razón, de determinar los fines y el sentido de la vida, de su vida y en consecuencia es también, un ser infra-lógico, infra-racional, carente de la facultad de conocer y reconocer la verdad del ser y el hacer El saber verdadero es saber para la libertad, sólo por ella el hombre deviene ser de valores, sólo en la libertad el hombre encuentra la verdad de la vida; por eso la crisis del lagos, que primero niega la libertad reduciendo al hombre a la necesidad y después lo hace diluyéndolo en la eventualidad del ser; en ambos casos el hombre pierde, con su libertad su identidad. (Del Palacio, 2004, p.28)

El desarrollo científico y tecnológico de la segunda mitad del siglo XX significó una alteración formidable en las relaciones del diseño cuyas repercusiones lo han transformado aceleradamente incluyendo las circunstancias de enseñanza y práctica profesional de los diseñadores, sin que hasta el momento sea posible precisar todas las consecuencias en el mundo de los valores y el sentido de la vida ni se haya replanteado su papel y fundamentos, mucho menos, sus nuevas relaciones con la conciencia ética que también ha sido privatizada como el mundo entero y el hombre mismo.

\section{Sospechas sobre la ética del Diseño}

Hace años se olvidó vincular la actividad humana a la propia del diseño en pro de lo que ha sustituido a elementos fundamentales de la ética. El valor del mercado con términos como emprendimiento, negocio, riesgo, dinero, éxito, todos ellos asuntos "excepcionales" materia de revisión curricular y profesional, son los asuntos "emblemáticos" que hoy nos ocupan y esto se dice con la mayor ironía posible. En términos generales la distinción radicó en la diferencia entre comportamiento y conducta, reservando ésta a la actividad racional, consciente y deliberada, de manera que se arribara a la tesis según la cual el diseño se refiere a esta última y se desembocaba en el tema de la libertad, para hacer propia del diseño la conducta libre, que implica responsabilidad y con ella la atribución de obligaciones y derechos prescritos por las normas. El primer tema ha tenido una variante esencial, que puede -junto con otros avances de la ciencia y la tecnología- originar nuevas maneras de entender del diseño, estrictamente conceptuales o normativas, en ambos casos las consecuencias implican nuevas formas de percibir al diseñador.

Hasta hace menos de cincuenta años el tema consistía en distinguir la conducta del diseñador del comportamiento de otros profesionales, hoy el tema se desplaza a la distinción de la conducta del diseñador del mentado comportamiento inteligente de las máquinas de pensar, de las computadoras, cuyo funcionamiento lógico sobrepasa la capacidad analítica del razonamiento del diseñador. Es así que la esencia humana del diseño, fincada en la razón e identificada con la capacidad de deducción lógica, queda en entredicho, esto 
apoyado también en las corrientes positivistas de la Filosofía o la Psicología que tienden a reducir toda conducta a los procesos de los cuales depende ocultando la libertad y con ella la responsabilidad inherente a todo diseñador y todo objeto diseñado.

Skinner en su texto Mas allá de la libertad y la dignidad (1972), redujo todo comportamiento humano a simple reacción ante los estímulos externos, negando la existencia del yo interno, donde precisamente residen libertad y dignidad, fuentes de compromiso, considerándolas creencias románticas y pre-científicas. Si el diseñador es privado del carácter racional, carecerá de libertad y dignidad, el diseño debe cambiar sus fundamentos junto con los bienes y valores que actualmente tutela en su noción más originaria.

El diseñador instrumentalista descargado de responsabilidad por su conducta, transformada en mero comportamiento determinado y controlado, semejante lo mismo al de las computadoras que al de artefactos artificiales reproductores de sus funciones parece colocado en un nuevo génesis donde tuviera que reencontrarse a sí mismo y recuperar la dignidad que ahora sólo simula. Se han olvidado las concepciones del diseño y los diseñadores como efecto de los más altos desarrollos de la cultura y la civilización que Tomás Maldonado, refiriendo a la dialéctica, enunció como las más fecundas trayectorias de la exploración científica acerca de las objetividades y subjetividades de la praxis humana. El diseño en sus inicios jamás fue entendido como una actividad insólita e inexplicable, de hecho una de los parteaguas epistemológicos de la disciplina fue la batalla contra las "cajas negras" que hoy han regresado para pringar el concepto en los chips de las computadoras privilegiando la oscilación constante entre la idea y la materialización vacua. Las formas de la razón simbólica ya no se identifican en los afanes de la inmediatez, la velocidad y el agobio por lo no sustancial.

Searle (2000) afirmó que el cerebro es la materialización de un programa de cómputo y su diferencia con una computadora electrónica, con la cual comparte un mismo algoritmo, radica sencillamente en el material del cual están hechos dejando creer que el cerebro no es sino una computadora digital.

Penrose en cambio señaló desde la transdisciplinariedad y el pensamiento complejo, los laberintos de la estructura cerebral explicando diferencias cuantitativas como la enorme diferencia entre el número de sinapsis posibles (más de 80,000) y las reducidas cuatro o seis compuertas lógicas de entrada y salida de una computadora, y aquellas diferencias cualitativas como la unicidad de la conciencia, imposible para la inteligencia artificial. El científico demostró mediante análisis llevados hasta los niveles de la cuántica que la conciencia no es algorítmica mientras, paradójicamente, si algo puede ser algorítmico en la mente humana es el inconsciente "en un nivel muy complicado que sería difícil desentrañar en detalle", es por ello que según el físico.

La formulación de juicios, que afirmo es la impronta de la conciencia, es ella misma algo sobre lo que la gente de la inteligencia artificial no tendrá ninguna idea de cómo programar en una computadora...los algoritmos por sí mismos nunca comprueban la verdad. Sería tan fácil hacer que un algoritmo produjera falsedades como hacer que produjera verdades... es esta capacidad para dis- 
tinguir [o intuir] en circunstancias apropiadas, verdad de falsedad [y belleza de fealdad] lo que constituye la impronta de la conciencia. (Penrose, 2002, p. 485-486)

Los diseñadores contemporáneos de la inteligencia artificial identifican la praxis con el pensamiento racional e intentan resolver necesidades y problemas de diseño según procesos algorítmicos en una inagotable cadena de simulaciones. Este fetichismo de la técnica tendría que ser superado por todos los que aspiren a captar el significado último de una nueva visión del diseño. A pesar de las tesis que mantienen al diseño a salvo de los determinismos científicos, razón, libertad y dignidad llegan a un punto en que se diluyen en la vida social con lo cual ética y diseño son despojados de su contenidos para ser enviados al pasado pre-racional del humanismo y la fantasía, sujetando al diseñador a formas que prescinden de ello para mantener las condiciones del control colectivo.

Los diseñadores al ignorar la filosofía pierden en la trivialidad sus problemas verdaderos; la persona deja de ser su destinatario y los mensajes, objetos o espacios correctos adquieren fines de control colectivo desligados del centro donde reside el ethos común. El valor humano es puesto en entredicho y el diseño padece su devaluación.

\section{Para concluir, nuevo principio para ethos y diseño}

El diseño comenzó el siglo XXI sumido en la misma crisis en que terminó el siglo XX, los signos de alarma no son atendidos y no se alteran los planes de los centros de enseñanza; a pesar de los desajustes cada vez más frecuentes y previsibles los organismos internacionales rectores del diseño enderezan sus esfuerzos para mantener el orden internacional -sea esto lo que se prefiera-, a costa del sacrificio de la gran masa de estudiantes y egresados de las carreras de diseño que paulatinamente se ven desempleados como parte de la generación sin futuro, callados por las voces oficiales que claman por la sustentabilidad de todo aquello que el sistema ha hecho insostenible. En el orden infralógico e infraético descansan los intereses dominantes y se degrada la dignidad profesional del diseño en nombre de la libertad de comercio y los derechos privados.

El foco del bien común en el diseño debe ser la persona, por ello el diseñador en esta dimensión ética además de creador es portador de valores. Ya desde Platón, más tarde con Agustín de Hipona y después con los grandes pensadores sobre el comportamiento ha quedado de manifiesto con toda claridad que la concepción religiosa, filosófica o científica que se tenga determina el ethos al cual se responde y da contenido al régimen moral que se construye. El diseñador no es ajeno a estos principios, la ética profesional siempre conlleva los vestigios del ethos familiar y social.

La equiparación hecha por Platón de las facultades mentales y los tipos de hombre (de oro o parte racional, plata o coraje y cobre o parte de los apetitos) integrantes de la polis ideal (verdadera) y sus funciones, según su naturaleza; 
[...] el dios que os modeló puso oro en la mezcla con que se generaron cuantos de vosotros son capaces de gobernar, por lo que son los que más valen; plata, en cambio, en la de los guardias, y hierro y bronce en las de los labradores y demás artesanos. Puesto que todos sois congéneres, la mayoría de las veces engendraréis hijos semejantes a vosotros mismos, pero puede darse el caso de que de un hombre de oro sea engendrado un hijo de plata, o de uno de plata uno de oro, y de modo análogo entre hombres diversos... el dios ordena que los gobernantes... vigilen intensamente qué metal se mezcla en la composición de las almas de sus hijos... si sus propios hijos nacen con una mezcla de bronce o de hierro, de ningún modo tendrán compasión (y) los arrojarán entre los artesanos o los labradores. Y si de éstos, a su vez, nace alguno con mezcla de oro o plata... los ascenderán entre los guardianes o los guardias...' (Platón, 1998, III, p. 169)

Bajo términos análogos están la antropología filosófica de la cual es precursor Agustín de Hipona; el hombre lobo del hombre de Hobbes, el buen salvaje de Rousseau, el hombre masa de Skinner, son ejemplos de la certidumbre que el ethos conduce a formas diferentes de organización social y distintos fines protectores de valores y bienes inmateriales. El mismo anarquismo, calumniado y deformado, niega todo poder heterónomo porque lleva a su consecuencia extrema la afirmación de que el hombre es un ser de razón y por ello no necesita de autoridad heterónoma alguna para hacer a cada momento lo que debe hacer conforme a ella.

El ethos subyacente a la idea del diseño como determinación normativa no es distinto al que afirma el diseño como sistema de dominio social; en ambos casos la relación poderdiseño queda determinada por el ethos en que ambos se fundan. Diseñar es en esencia razón práctica porque se identifica con el hacer humano, es saber para hacer, para guiar al hombre en la construcción del mundo donde es.

La razón práctica se limita a establecer dos fines estrechamente relacionados: constitúyete en ser autónomo y comprométete en la formación de un orden civil que garantice la autonomía de todos los participantes (el reino de los fines). La definición de estos fines es una consecuencia de reconocer que la libertad es condición necesaria del discurso moral. (Serrano, 2005, p. 125)

Hasta los conocimientos teóricos en apariencia sin sentido práctico apuntan hacia el hacer y derivan de él. El diseñador se identifica y reconoce como ser de relación, su ethos concierne a la empatía comunicativa, objetual o espacial con los otros con quienes forma el nosotros de la sociedad a la cual pertenece y en el círculo de su vida íntima el tú.

El lógos en el Diseño es objetivo y subjetivo, contiene al entorno y al ser humano en nexos específicos, contiene el ethos que se construye a sí mismo en lo diseñado que hace para los otros, es guía que sabe y orienta la conducta, supone la convergencia de razón teorética, razón práctica y lógica que acude a la primera para los fines de la segunda. El lógos es lógos en especulación y acción, en él radican la sabiduría y la virtud del diseño, el diseñador y lo diseñado. 
El hacer y responsabilidad del diseñador no son sólo ante él mismo, siempre son simultáneos, ante y con otros, con otro yo, sin el cual carecen de sentido; el carácter racional del ethos del diseño es relacional y dialógico, se actualiza y objetiva en las relaciones comunicativas, objetuales y espaciales, no en la individualidad fuera del mundo.

Hay que comprender que ningún valor ético es en verdad objetivo, ni actualizable, en la existencia aislada de diseñador, así como no hay razón de uno, tampoco hay ethos de uno. Los valores en diseño sólo son posibles y dables en las relaciones intersubjetivas diseñador-diseñado-receptor, ningún valor es genuino como responsabilidad individual ante uno mismo, ante el tribunal desconocido de su conciencia y su subjetividad, en ellas está presente de manera inevitable el ethos común, que proviene del hacer. La conciencia ética profesional también proviene del juicio común por el simple hecho de ser relacional y dialógica, por lo que también llama a la conciencia propia y es autoconciencia.

Uno de los momentos cruciales del ascenso de la conciencia ética en el Diseño radica en el descubrimiento de que la responsabilidad por la conducta propia depende de la decisión racional sobre el juicio que pronuncia la razón sobre el bien o el mal del hacer que no depende de fuerzas irresistibles, ni de costumbres, ni de la comunidad. Este ethos para el diseñador es una claridad que se revela en los resultados de las acciones proyectuales, como afirmó Sócrates, se trata de la razón consciente de sí, el fundamento legítimo del ethos, que es, sobre todo, saber de pertenencia en la sociedad a la cual se pertenece, que es identidad, lenguaje, habla, expresión y reflexión. El ethos cobija al diseñador desde su escolarización y le proporciona los elementos indispensables para reconocerse y cobrar conciencia de sí. Es, ante todo un orden que recoge los valores implícitos, los conserva y trasmite por medio de la formación y las normas, estructura imprescindible que tutela los valores sociales en los cuales descansa el diseño.

Los principios de la disciplina deben sintetizar el ethos social proyectado desde la estructura epistemológica delimitando lo permitido y lo prohibido, aun cuando su violación no conduzca a consecuencia individual alguna, no se puede negar el ethos que da cuenta de ello. El ethos ha de proporcionar la dimensión humana del diseño, nada, absolutamente nada puede serle ajeno, ni el conocimiento, ni la economía, ni la tecnología, ni alguna otra actividad social. De igual manera, los sentimientos, el deber propio o las pasiones del diseñador no están exentos de contenido ético, por más que respondan a principios distintos y juicios valorativos de construcción contradictorios.

Sirvan estas reflexiones para marcar un alto en el camino y considerar si nos encontramos en la posibilidad de tomar decisiones sobre el ethos del Diseño y los diseñadores. Esta es la primera y más importante acción de la responsabilidad social del Diseño, ella per se atraerá las acciones que conduzcan a una mejor vida de las personas a través del diseñar. 


\section{Lista de Referencias Bibliográficas}

Azuela de la Cueva, A. (2005) Arte y poder. México: El Colegio de Michoacán / Fondo de Cultura Económica

Balzat, Olivier (Ed.) (2002) Le concept d'identité. Vivre ensemble autrement. Bélgica: Annoncer le Colueur /CBAI / CGE / Info-Sud Belgique / ITECO, pp. 41-44

Bauman, Zygmunt (2011) 2. De peregrino a turista, o una breve historia de la identidad, en Hall, S.; du Gay, Paul (Comps.) Cuestiones de identidad cultural. Buenos Aires: Amorrortu, pp. 40-68

Bauman, Zygmunt (2015) Ceguera moral. Barcelona: Paidós

Del Palacio Díaz, Alejandro (2004) Ética para todos. México: UAM / CEIDSA

Fandiño Barros, Yolanda (2014) "La otredad y la discriminación de géneros" en Advocatus. Barranquilla: Universidad Libre Seccional, vol. 11, no. 23, pp. 49-57

Fernández Paniagua, José María (2009) "La enajenación en la sociedad capitalista. Una aproximación a las tesis de Erich Fromm” en Germinal. Revista de estudios libertarios. España: Germinal, número 8, octubre, pp. 59-86

Gudynas, Eduardo (2016) "Alternativas al Desarrollo y buen vivir" en El Buen Vivir como paradigma societal alternativo. Madrid: Economistas sin Fronteras. Dossiers EsF, 23, pp. 6-11

Giddens, A. (1990) The Consequences of Modernity. Cambridge: Polity Press

Giménez, G. (1995) Modernización, Cultura e Identidad Social. Espiral. I (2), 35-55, http:// www.redalyc.org/articulo.oa?id=13810203

Goffman, Erving (2012) Estigma. 2a edición. Buenos Aires: Amorrortu

Hall Stuart (1992) The Question of Cultural Identity. En Stuart, H. et al (eds.) Modernity and its Futures. Cambridge: Polity Press, pp. 273-316

Heidegger, M. (1990) Identidad y diferencia. Barcelona: Anthropos

Lipovetsky, G. y Charles, S. (2014) Los tiempos modernos. Barcelona: Anagrama

Maldonado, T. (1977) Vanguardia y racionalidad. Barcelona: Gustavo Gili

Maquiavelo, N. (2010) El Príncipe. México: Gandhi

Packard, V. (2007) Hidden Persuaders (1a reimp.) USA: IG Publishing

Parra Luna, F. (2004) "Hacia una teoría axiológica de la sociedad" en Papers 72. Visions alternatives sobre la societat i la realitat social. Barcelona: Universitat Autónoma de Barcelona, pp. 31-65

Penrose, R. (2002) La mente nueva del Emperador. En torno a la cibernética, la mente y las leyes de la Física. México: FCE

Platón (1988) Diálogos IV República. Madrid: Editorial Gredos (Biblioteca Clásica Gredos, 94)

Searle, J. R. (2000) El misterio de la conciencia Barcelona: Paidós Ibérica (Studio, 141)

Serrano Gómez, E. (2005) “Reflexiones sobre la razón práctica” en Signos Filosóficos. México: Universidad Autónoma Metropolitana, vol. VII, enero-junio, pp. 121-126

Skinner, B.F. (1972) Más allá de la libertad y la dignidad. Barcelona: Fontanella

Toynbee, A. J. (1974) A Study of History. USA: Dell Publishing / Oxford University Press

Van Knippenberg, D. (1999) Social Identity and Persuasion. En Abrams D., Hogg, M. (Eds.) Social Identity and social cognition. USA: Blackwell Publishing

Wittgenstein, L. (1989) Tractatus logico-philosophicus. Madrid: Alianza Editorial 


\begin{abstract}
Ethos is the principle that should stimulate every designer, it is a kind of interior space in which self-awareness and the world where it exists and exists. In the ethos, the designer knows and recognizes himself, in him resides his discernment and makes sense the accumulation of relationships in which he expresses himself, he encourages the behaviour that gives him existence and unifies his ability to build the place where he finds security and protection of his well-being and that of others. A private existence of being and life turns the ethos into pathos that loses the designer into nothing. Never before have technological resources allowed the construction of such a complete and effective system of domination to design through the exploitation of its own momentum, which in more ways than one is a reflection of that reality that weighs on the atomized and saddened masses, isolated in their own worlds that are recognized as leaks from a context in which they cannot live, which has ceased to be a home. Due to the above, the epistemological relations of Design are lowered in a process of absolute ideologization, eliminating the theoretical controversy and giving way to the mono-cultural domain that destroys thought and knowledge by reducing the critical capacity and ethical consciousness that produces the designer infralogical and infraethical, protagonist of the bankruptcy of postmodern values that ends up denying the concept and the world where the designer is and acts. The conceptions of design and designers seem to be forgotten as an effect of the highest developments in culture and civilization that Tomás Maldonado, referring to dialectics, enunciated as the most fruitful trajectories of scientific exploration regarding the objectivities and subjectivities of human praxis. This article will postulate a new beginning for ethos and design.
\end{abstract}

Keywords: ethics - design - abstraction - reflection - praxis

Resumo: Ethos é o princípio que deve estimular todo designer, é um tipo de espaço interior no qual a autoconsciência e o mundo onde ele existe e existe. No ethos, o projetista conhece e se reconhece, nele reside seu discernimento e faz sentido o acúmulo de relações em que se expressa, incentiva o comportamento que lhe dá existência e unifica sua capacidade de construir o local onde ele encontra segurança e proteção de seu bem-estar e dos outros. Uma existência privada de ser e vida transforma o ethos em pathos que perde o designer em nada. Nunca antes os recursos tecnológicos permitiram a construção de um sistema de dominação tão completo e eficaz, explorando seu próprio momento, que de várias maneiras reflete a realidade que pesa sobre as massas atomizadas e entristecidas, isoladas em suas mundos próprios que são reconhecidos como vazamentos de um contexto em que não podem viver, que deixou de ser um lar. Pelo exposto, as relações epistemológicas do Design são reduzidas em um processo de ideologização absoluta, eliminando a controvérsia teórica e dando lugar ao domínio monocultural que destrói o pensamento e o conhecimento, reduzindo a capacidade crítica e a consciência ética que produz o designer. infralógico e infraético, protagonista da falência dos valores pós-modernos que acaba negando o conceito e o mundo em que o designer está e atua. As concepções de design e designers parecem esquecidas como efeito dos mais altos desenvolvimentos na cultura e na 
civilização que Tomás Maldonado, referindo-se à dialética, enunciou como as trajetórias mais frutíferas da exploração científica sobre as objetividades e subjetividades da práxis humana. Este artigo irá postar um novo começo para ethos e design.

Palavras chave: ética - design - abstração - reflexão - práxis

[Las traducciones de los abstracts fueron supervisadas por el autor de cada artículo] 